\title{
William Carlos Williams' Young Woman at a Window: An in-depth analysis based on the Principles of Imagist Manifesto
}

\author{
Dhanya G. \\ Assistant Professor, Department of English, Vignan Pharmacy College, Guntur, Andhra Pradesh, India
}

\begin{abstract}
This paper centers on William Carlos Williams' poem Young Woman at a Window, with an aim to explore the two versions of the poem Young Woman at a Window. The key method of this paper is textual analysis.The paper examines the text with reference to the principles of imagist manifesto. An in-depth analysis of the two versions states that the second version is 'more imagist', a modernist retrospection than animprovement, of the first.
\end{abstract}

Key words: Imagism, imagist manifesto, young woman, window.

\section{Introduction}

Modernism in poetry had many beginnings; imagism marks just one. Imagism is defined as "a movement in poetry ... aiming at clarity of expression through the use of precise visual images." It began as the abandonment of, and revolt against, the Romantic and Victorian poetic traditions. This movement in poetry originated in 1912 and represented by Ezra Pound, Amy Lowell, and others, aiming at clarity of expression through the use of precise visual images. Imagism was a successor to the French Symbolist movement, when Symbolism had an affinity with music, Imagism sought analogy with sculpture. Poets like John Gould Fletcher, Harriet Monroe, Richard Aldington,Conrad Aiken, Marianne Moore, Wallace Stevens, D.H. Lawrence, and T.S. Eliot were influenced by imagism in their own poetry. The Imagists wrote succinct verse of dry clarity and hard outline in which an exact visual image made a total poetic statement. Imagists were against use of late Victorian wordiness, flowery figuration and "beautiful" abstraction. They rejected such qualities through staunch assertions demanding concision, concentration, precise visuals and a sort of super-focused emotive objectivity.

The Imagist manifesto focused on some principles which became the essence of imagist poetry. The first principle asserts to use the language of common speech, but to employ the exact word, not the nearly-exact, nor the merely decorative word. Principle two, affirms to Imagists' belief that the individuality of a poet may often be better expressed in free verse than in conventional forms. The third principle stated that absolute freedom should be given to the poet in the choice of subject. The fourth principle can be remarked as the quintessence of imagist poetry, which is to present an image. Though they did not belong to school of painters, imagists believed that poetry should render particulars exactly and not deal in vague generalities, however magnificent and sonorous. It is for this reason that they opposed the cosmic poet, who shirks the real difficulties of hisart. Principle five emphasizes on producingpoetry that is hard and clear, never blurred nor indefinite; and principle six states that concentration is of the very essence of poetry.

William Carlos Williams' poetry is "the Imagism of 1912, self-transcended" said, R.P. Blackmur. He invented an entirely fresh and uniquely American form of poetry whose subject matter centered on everyday circumstances of life and the lives of common people. William Carlos Williams (1883-1963) was a "Whitmanian" in the beginning. The Williams of the late 1910s and 1920s was a poet fascinated by currents of formal experimentation - imagism, Dadaism, cubism and, a little later, objectivism. The Collected poems of William Carlos Williams: Volume 1 was published in the '40s and '50s. This period of Williams, from 1909 to 1939 contributed great poetic works to American literature. Young woman at a window version 1\&2,Smell, Portrait of Lady Etc. are some poems by Williams that befit the imagist moment.

\section{Analysis}

There are two versions for the poem "Young Woman at a Window" by William Carlos Williams. This poem was published in 1934, one poem on top of another in the Westminster Magazine which was published in Atlanta, Georgia, USA. But, at the end of the volume, followed a footnote which indicated that the poem was published together but eventually Williams dropped the first poem and only allowed the second poem to be republished. And it was only in this volume that the two were brought back together. One of these versions was published and the other remained unpublished during the poet's lifetime; this manuscript version was found by scholars among Williams' papers and was eventually published. It is assumed that one version was a rewriting or reworking of the other, or that he wrote one and then revised it, and that the effort of revision produced the other. We have no particular evidence, other than what we might find in the poem itself, to believe that Williams 
wrote "Young Woman at a Window" under the influence of imagism. We don't know that he meant this poem to adhere to imagist principles. Nonetheless, the second of these two Williams poems is considered to be more imagist than the first.

\section{Williams, "Young Woman at a Window" (version 1) \\ While she sits \\ there}

with tears on

her cheek

her cheek on

her hand

thislittle child

who robs her

knows nothing of

his theft

but rubs his

nose

Williams, "Young Woman at a Window" (version 2)

She sits with

tears on

her cheek

her cheek on

her hand

the child

in her lap

his nose

pressed

to the glass

This study aims to lookclosely at the poems and to argue that interpretative position - that version 2 is "more imagist" when compared to version 1 based on theprinciples of imagist manifesto. Is Version 2 a revision made by Williams, which brings the poem more closely to the goals of Imagism? To make this case, we should analyze the two versions of the poem based on several arguments from the ImagistManifesto that may have been guiding principles in the transformation of this poem.

William Carlos Williams came up with the concept of the "variable foot", vaguely referred to Williams' method of determining line breaks. This concept is used in Young Woman at a window. The Paris Review called it "a metrical device to resolve the conflict between form and freedom in verse." The poet makes this poem, "with such intensity of perception that it lives with an intrinsic movement of its own to verify its authenticity." The two version of the same poem or we looked at it another way, two different poems that are close to each other. Both called Young Woman, Young Woman at a Window, by William Carlos Williams. In both the versions of "Young Woman at a Window" particulars are rendered exactly which makes the poem splendid and resonant. In the two versions of "Young Woman at a Window', Williams presents basically the same scene, but with different emphases and, hence, leaves his reader the objectionable task of detailing the differences between both. The subject chosen by the poet is very simple making the reader wonder about the content in it. In the poem the poet uses the language of common speech. In both versions of the poem we find use of simple words, but at the same time the poet employs the exact word and not a decorative word. The poet expresses his ideas in free verse. He does not employ consistent meter patterns, rhyme, or any other musical pattern. It thus tends to follow the rhythm of natural speech. It is not necessarily just the words themselves that construct meaning; rather, it is the movement of the poems that changes the meaning from the first version to the second. In contrasting the two versions of "Young Woman at a Window," the grammatical placement and 
grouping of the stanzas affects the forward motion of the poem, thus effecting our overall perception of the young woman, the little child and the tears on her cheek.

Principle 5 argues for crisp, clear, and definite images, without any flowery language, while Principle 1 argues for precision and against embellishment. It is by looking at the poem in the light of these two principles we can most easily see the transformation Williams performed on this poem.

In Version 1, there is a narrative; a temporal story that is being told that includes characters, plot, and movement. The child is active (he "robs"); the mother is located in time that she moves through ("While she was sitting"). You are even invited into the minds and thoughts of the characters (the child "knows nothing"). In short, Williams is telling a story with version 1 , and in the storytelling arc he is suggesting emotional and intellectual responses to the narrative. Version 1 is structured, fascinatingly, as a periodic sentence in verse - a dependent clause, followed by two prepositional phrases and ending with two coordinating independent clauses. There is an inescapable sonorousness that seems, at least, to ignore or, more seriously, to contradict the tenets of the imagist manifesto.

In the first version, the poet uses time and position...while she sits there. The word "while" of the first stanza of the second version of the poem is not clearly defined. The reader does not know what length of time this word represents. The reader also does not know where the woman is sitting. This breaks the conduct of imagism.

The two identities are almost separate throughout the entire poem, with the first three stanzas referring only to 'her,' and the final two stanzas referring only to 'him.' The only overlap is within fifth stanza through the action of the child robbing her.

The young woman is with tears and this 'little child who robs her...', suggests that there is one child in front of her but her hands does not hold the child. It is slightly detached from the mother image. Is this child the cause of her tear-stricken cheek? The first three stanzas move in a way that allows a pause between stanzas: "while she sits there" stands on its own; the stanza could end there. It goes on, however, to add "with tears on her cheek"- . Then, the poet adds "her cheek on her hand." These first three stanzas, though they add information, could standindependent from one another. The second three stanzas shift the focus to "this little child who robs her." The child, based on the structure of the poem, is literally separate from the mother.

Though the structure and movement of the lines - the fact that the description of the child is a separate grouping of stanzas entirely, adds an authentic feeling of detachment for the reader. The lines: child "knows nothing of his theft / but rubs his nose, annoys the reader on, what did the child rob? ---is it the love and affection of the young woman or is the woman his mother? Do her tears indicate her longing for a child like him? Does she urge to devote her happiness and tears for this child? The meaning of Williams' words in the fourth and fifth stanzas of the first version of the poem is not pronounced "this little child / who robs her // knows nothing of / his theft". The reader does not know if the child's theft is literal or figurative. The intention of these words is blurred; therefore it goes against imagist principles. The words "this" and "little" (describing the child) are taken away in the second version of the poem because of their decorative role.

In the first version, guilt is more directly attributed to the child linguistically through the claim that he 'robs' the woman. However, it is likely that this theft is abstract rather than that he has stolen something. Perhaps he is robbing her physically of energy and liveliness. Perhaps it is more emotional, robbing her of freedom and possibilities. Perhaps he robs her of her very essence and individuality, consisting of partly her and her lover. Whichever conclusion is drawn, it is written as open to interpretation, and this may be seen as failing under imagist constructions as 'non-exact' and potentially blurry.

The second version has eliminated a great deal of "poetic" embellishment, in favor of the presentation of a single, static image. Version 2, however, is structured more tightly, as far as syntax is concerned - the main idea supported by four participial phrases. This fragmented presentation, with its sparer lines, satisfies the imagist objective, of "a poetry that is hard and clean, never blurred or indefinite."

In version 2, all of that explicit narration is stripped away, in favor of a single, photographic, or sculptural image. No longer are there characters that move, think, and act within the arc of the poem itself. There is neither a sense of time, nor a story unfolding. In its place, Williams has left us with a single image, in which we are invited to create our own narrative. There is still emotional content in the piece, but that emotional content is evoked in the reader through our own emotional associations with specific iconic imagery, such as tears, a cheek on a hand, a child in a lap, and a nose pressed against the glass. This is Imagism in its purest form, in which the poet as storyteller has stepped back and allowed the visual, descriptive, photographic, and sculptural language to carry the entire narrative of the poem.

This transformation of the piece embodies Principle 4 of the Imagist Manifesto beautifully. It presents an image precisely and richly. As Williams stated, "no ideas but in things", Version 2 of "Young Woman at a Window" is chock full of ideas, but those ideas are fully embodied in the visual and descriptive images that Williams has concentrated into this beautiful, 24 word poem. And as such, it remains an excellent example of Imagism. 
When the first version of the poem presents the image of a woman robbed by her child the second version of the poem presents the image of a crying woman with a child on her lap.

The flow of the stanzas is very gentle and smooth, it becomes unclear whether the child is the source of her tears; and the mother and child are connected rather than detached. The woman is crying the same tears as in the first version. It is not the words themselves that make the meaning. It is, instead, the structure that makes the poem have authenticity and meaning. Version 2 is more stringently imagist in that it is a snapshot of the mother and child. The interpretation of why she is crying is more open to us. The first two stanzas end with a preposition - which causes readers to move forward in search of the next noun. The woman here, "sits with tears on"... on her cheek." Then the poem moves forward in the same stanza, pairing "Her cheek" with "Her cheek on"..."Her hand." The middle stanza in this poem marries "her hand" and "the child" which emphasizes the relation between the mother and the child. The emotion of the mother who cares the child even with her touch and their bond is aptly visualized. This is almost a circular description of contact, her hand on herself, him in her lap, and the suggestion through structure that his nose is in her lap too, until we read that it is 'pressed/to the glass.' The poem is like one long sentence that makes a statement. Literally, the woman is connected with the child through the structure of the poem. The final stanzas continue to blend together the woman and child, since "the child" is "in her lap/his nose/ pressed to the glass. The two people overlap twice in the second version through 'her hand/the child' and 'in her lap/his nose.'

The subtle suggestion that his nose was in her lap creates the picture of a child burying their head quite innocently, but the mention of his nose also has similar underlying connotations to William's nose in the poem 'Smell.'

Nose is an image which states of the taste and senses of everything in this world and glass refers to the transparency of life. The poet aims at clarity of expression through the use of precise visual images. In version 2 ; the idea is presented in the form of an image where we can visualize the young woman and her hands holding the child. In stanza four of the second version of the poem, the lines "in her lap/his nose" bring the image of a child burying his head in his mother's lap to mind. I think these lines are more connected rather than interpreting the poem as the child pressing his nose against the glass. This is because the lines are in the same stanza, thus further associated with each other.

The lines "pressed/to the glass" of stanza five in the second poem evoke a sense of hardness that is perfected by Williams' distinct word choice. Glass is a hard object, while the word "nose", the last word of the first version of the poem, creates a soft, lingering sound. The lines "with tears on / her cheek" make it are clear in both versions of the poem that the tears are on her cheeks. In both of these poems it is also clear that her cheek rests on her hand.

In stanza six of the first version of the poem, the child rubbing his nose could be interpreted in two ways. If the child literally robbed his mother, he could be rubbing his nose at her. If the child figuratively robbed his mother, the child could be rubbing his nose because he was crying.

Interestingly, the second version does not attempt to attribute blame to the child or spell out any more meaning than can be gained through observation. In does indeed construct an image, and it does not digress from what can be seen within the picture. It reads like a narrative, or a description of a photograph.

We find that there is the tonal difference between the two versions. Version 1 presents a sadder woman, with whom it is easier for the reader to empathize. She has been robbed by an innocent who in his ignorance simply rubs his nose. There is less subjective melancholy, more detached objectivity in Version 2. While we look at these two versions from far away, they're basically the same, roughly the same story. So, clearly Williams is not telling a story, he's a poet of great condensation, even in version 1 , which is a little longer than version 2 or say a radically condensed version of the narrative.

His interpretation of the subjects on the variation is a kind of editorializing, where in version 1 we see Williams telling as some stuff instead of showing us. There are much of narrative arcs. We've got the sense that she's in sorrow. The child is causing her pain. We get the child, the sense of the child's innocence. He's rubbing his nose against the glass, but has no idea of the fact he has on his mother. We get the sense of duration in one with the beginning, while whereas in version two it's much more of an image.

We see a room. In the room there is a woman sitting on a chair with. She seems to be alone. A child on her lap, presumably her own child and their both facing a window, looking out the window and the child is a little oblivious to, to the mother. In both versions he's to some degree oblivious. And in the second one, his nose is pressed against the glass, he's looking Out of the glass outside into the future, presumably she is too. They're both there in that scene, but they're looking for something. We find some difference between those two gestures. The child is rubbing his nose at the end of the first version. And the child pressed to the glass? In the first one, he's not necessarily looking outside. The glass is presumably the window of the title. In the version 1 the child could, just be doing anything, like attending to his immediate needs, going to ask you to rub your nose, in imitation of that.

The next thought in the readers mind would be "why would a child be oblivious in general?"Well, he is a child and there are a lot of things he don't know.He is also not necessarily conscious of his mother's, like, 
emotional life. So, he's pretty focused on his own, and we can also assume that his nose is running and he stops to wipe his nose or may be playing maybe with his mother to attain her attention. He can probably sense that something's up with her but not quite. And in the first version, we explicitly get that he knows nothing of his theft but also, of how his relationship is with his mother. I think imagism is more on the showing rather than the editorializing or telling.

It's not clear whether Williams is specifically under the influence of images, and here the poem is written in the '30s and his images phase is in the teens, but nonetheless he's that kind of poet. So, in the poem we have, 'knows nothing of his theft' and 'rubs his nose'. He knows nothing of his thefts -Why? Because, it shows us by him rubbing his nose that he's oblivious to the sorrow of his mother. He's just kind of there looking around being a kid. However, the case that rubbing his nose is open-ended and ambiguous, whereas 'knows nothing' of the step seems psychologically more precise. But here, as we are considering the project of images we focus on presenting an image than a psychology or to Interpretation of a situation. Imagism can be open ended as long as it's imagistic, because rubbing his nose, though it's not clear and is open ended, but it's a wonderful image. Therefore, sacrificing a little specificity in favor of the strong image can be accepted.

Further, when we think on the two versions what strikes us most is the length of the poem. The second version of Williams "Young Woman at a Window" is certainly more concise, consisting of just 23 words. One critical aspect of Imagism is embodied in Principle 6 from the Manifesto, where it is stated that "concentration is the very essence of poetry". Clearly, version 2 is a "concentrated" form of Version 1, if in no other way, simply in length. Version 2 cuts down the length of version 1 by 6 word (from 29 to 23). But "concentration" in this point of the manifesto likely means more than just reducing the number of words and characters on the page. It should be noted that this improves the clarity.

This economy of language seems to conform to Pound's definition of imagism. The key components of this version are pronouns 'she,' 'her,' 'his,' (used 6 times) and prepositions 'on,' 'in,' 'with,' and 'to' (used 5 times). These account for nearly half of the words used within the poem. There are just two verbs, two actions taking place, 'sits' and 'pressed.' The rest of the poems consists of things, nouns, 'tears,' 'cheek,' 'hand,' 'child,' 'lap,' 'nose,' 'glass,' and finally two definite articles 'the.' Simple language is a feature of imagism, so it could be argued that these limited words being repeated for effect are indeed an example of imagism. Although the number of different words may be small, there are still 23 words in the entire poem. The clarity of the picture is arguably clearer here.

Perhaps, it's an imagist principle that the poem is more condensed in the second version. But maybe it's because it actually conveys more of that sense of heartbreak when the poet takes the effort to eliminate the description. Further, in the first version, there's a "While" in the first line which places the reader. For the speaker, at a distance, from the woman and the child, but in the second, it feels more like a memory or something that comes in full force.

The first version could be a little bit sentimentalized, where as the second is sort of sharper. There's a huge difference in the grammar with the wild preposition, the second one is more practical; and the syntax is less, properly configured. It's a complete sentence. There's a subordinate clause. At the beginning the word 'while' suggests duration, simultaneity and temporality.

While she sits there/ with tears on her cheek/ her cheek on her hand /this little child. This little child is the subject, the grammatical subject. And the verb is, 'Knows nothing and rubs' or both rubs. So while she sits there; tears on her cheek, her cheek in her hand and that's where there will be a comma and the whole thing hinges.The motion, of the poem, then, is sort of driving to this child by, by way of the grammar. The woman here is this subordinated grammatically. The first one has more resolution in terms of duration and simultaneously, the mother is doing one thing while the child, is doing another thing. So we have these two separate things. And it's not clear how they're connected other than that they're happening at the same time. The second is very different, where, we get the subject right away; there's no Subject and verb right away - /She sits. /tears on / her cheek/ resembling the hanging clauses. So 'with tears on her cheek, her cheek on her hands, the trials in her lap, his nose pressed to the glass.' But, like, we have the verb and the subject right away. And the rest is a series of prepositional phrases namely with, on, in and to. She sits with tears on her cheek...with a series of precisely rendered phrases and lineation this poem creates a kind of modern Structure, say, that of a machine, 'the poem is a machine'. So, it's a series of prepositional dependencies. It sits with tears on her cheek/Cheek on her hand/ Child in the lap/and his nose Pressed to the glass. There's a lot of pathos in this scene and more pathos in the first, because there's a robbery, to assume a usage of metaphor, life robbery. Her life is not hers anymore. As he robs her as it were, here, the word theft is a metaphor, he's not.

The second version on the other hand, is more imagistic in the sense that the metaphorical content got removed. The reader wonders why the young woman is alone. The natural assumption about the help that she could get, leads us to a new character. There's a father, we know that there's a father, we have a mother and a child, so there's a father and the father's not there. In the second version of poem she sits with tears on her cheek, her cheek on her hand, the child on her lap, his nose pressed to the glass - here, the structure of the words befit the point. The form delivers a lot of the content. The structure of the poem helps us understand 
what's going on. We get a much more severe impression of that sense of dissent which follows through the whole poem. It goes from her eyes, to the tears on her cheek, own to the child, and we get this sort of intuitive sense that there's something lacking, something missing. The poem depicts the portrait of the window and we see the lonely inside, or the frustrated inside. The second version is more condensed, more positional. There's certain iconography that might be referred to in here - traditional iconography of a mother and child, a Madonna and child, Mary and Jesus.

\section{Conclusion}

Though there is no substantive superiority of one version over the other; after analyzing the two versions of Young Woman at a Window, it is found that there are varying degrees of imagism. Version 2 is the poetic equivalent of whatever alteration the painter does to his masterpiece the next morning when he awakes newly inspired. Both versions are open in some ways, but the clarity of image that can be drawn out of the second version makes it more significant and fitting within imagist poetry. A close analysis based on the principles of imagist manifesto brings one to the conclusion that the second version is a modernist retrospection or refinement, more than animprovement, of the first. What seems to have motivated Williams toward this end may have been his quest for imagist purity.

\section{Reference}

[1]. Abrams, M.H. 1993. A Glossary of Literary Terms, Prism Books Pvt. Ltd. , Bangalore, p86.

[2]. http://www.poetryfoundation.org/bio/william-carlos-williams

[3]. http://www.theotherwilliam.blogspot.in/2012/02/close-reading-part-1.html

[4]. https://www.coursera.org/course/modernpoetry

[5]. https://www.poets.org/imagism

[6]. Williams, Williams Carlos. 1986. Young Woman at a Window, In The Collected Poems of William Carlos Williams, New Directions Books, New York, Vol. 1 p373.

[7]. www.writing.upenn.edu/ alfilreis/88v/window2.html 